\title{
Stabilization and Two Way Shape Memory Effect in Cu-Al-Mn Alloys Transforming at Elevated Temperatures
}

\author{
J. Dutkiewicz, J. Pons* and E. Cesari* \\ Institute of Metallurgy and Materials Science of the Polish Academy of Sciences, ul. Reymonta 25, \\ 30-059 Krakow, Poland \\ * Departament de Física, Universitat de les Illes Balears, Ctra. de Valldemossa km. 7.5, \\ 07071 Palma de Mallorca, Spain
}

\begin{abstract}
Stabilization of martensite and two way shape memory effect (TWSME) was studied in $\mathrm{Cu}-\mathrm{Al}-\mathrm{Mn}$ alloys containing 9.7-11.8 $\mathrm{wt} \% \mathrm{Al}$, and 3.0-9.25 $\mathrm{wt} \% \mathrm{Mn}$, which were quenched to various temperatures. The transforming temperatures were in the range -70 to $+220^{\circ} \mathrm{C}$. The majority of alloys quenched directly to martensite did not show reverse transformation on heating due to stabilization and further tempering of martensite. However, when quenched to temperatures several degrees above Af, reversible transformation was observed in all the investigated alloys. The TWSME training was performed by a repetitive cooling under external stress and heating after unloading. In alloys transforming below $150^{\circ} \mathrm{C}$ saturation of TWSME occurred between 50 and 80 training cycles, while in alloys transforming at higher temperatures it was earlier, i.e. after 20-40 training cycles. The latter alloys have shown TWSME elongation of about $0.4 \%$, while alloys transforming at lower temperatures attained up to $1.4 \%$ higher TWSME. DSC studies revealed a reduction in transformation heat by about $30 \%$ after training, which can be related to the presence of residual martensite detected by optical microscopy. This martensite could not be removed after flash or slow heating in the calorimeter for any of the investigated alloys, apparently prone to martensite stabilization. Transmission electron microscope studies revealed the presence of dislocation bands in low temperature transforming alloys and almost homogeneous distribution of dislocations in alloys transforming at higher temperatures. This fact explains the poor training ability of alloys transforming at higher temperatures, since the thermal mobility of dislocations prevents formation of stacks favouring nucleation and progress of trained variants. However, the role of residual martensite in the training process cannot be neglected.
\end{abstract}

\section{INTRODUCTION}

Two way shape memory effect in copper based alloys has been mainly studied in alloys transforming below $120^{\circ} \mathrm{C}$ [1-7]. The only work found where transformation temperatures approach $200^{\circ} \mathrm{C}$ [8] was performed using $\mathrm{Cu}-\mathrm{Al}-\mathrm{Ni}$ alloys. The authors reported there that the raising of the highest temperature during training from 190 to $200^{\circ} \mathrm{C}$ lowered the training efficiency, which was attributed to the annihilation of dislocations formed during the training cycles. A residual deformation was observed after training, which was attributed to two major components, i.e. plastic deformation and residual stabilised martensite, similarly as observed in $\mathrm{Cu}-\mathrm{Zn}-\mathrm{Al}$ alloys [2] with lower transformation temperatures. The residual martensite has been reported not to have an important effect on the TWSME [1], since it can be removed by overheating and this fact does not deteriorate the TWSME, although it is well known that a suitable method to induce the TWSME consist in the stabilisation of stress induced martensite $[5,6]$. A calorimetric investigation of $\mathrm{Cu}-\mathrm{Zn}-\mathrm{Al}$ alloy with induced TWSME has shown that the heat of martensitic transformation of the trained alloy is about $25 \%$ lower than that of one way memory [9]. Authors attribute the differences to different variants, but it seems that the residual martensite can also be one of the reasons. It is known that the $\mathrm{Cu}-\mathrm{Al}-\mathrm{Mn}$ alloys transforming at subambient temperatures show a good ability for TWSME $[7,10]$. However this alloy system can exhibit a reversible martensitic transformation 
up to $300^{\circ} \mathrm{C}$ [11]. Therefore, it is of interest to study the TWSME in Cu-Al-Mn alloys transforming at elevated temperatures (close to $200^{\circ} \mathrm{C}$ ) and to compare their training ability to that of $\mathrm{Cu}-\mathrm{Al}-\mathrm{Ni}$ alloys.

\section{EXPERIMENTAL PROCEDURE}

The alloy compositions and the characteristic transformation temperatures are listed in Table 1. All alloys contained a small addition of Ti5B as a grain refiner, leading to a grain size not exceeding $100 \mu \mathrm{m}$. The investigated alloys were cast in a Balzers vacuum induction furnace under protective argon atmosphere and hot rolled. The specimens were heat treated at $850^{\circ} \mathrm{C}$ and quenched either in water or in a melted salt bath at different temperatures. Martensitic transformation temperatures were measured using a Perkin Elmer DSC-4 calorimeter. Table 1 shows the transformation temperatures of samples quenched to temperatures several degrees above Af.

Table 1

\begin{tabular}{|l|l|l|l|l|r|r|r|r|}
\hline Alloy & wt\% Cu & wt\%Al & wt\% Mn & wt\%Ti5B & $\mathrm{M}_{\mathrm{f}}\left({ }^{\circ} \mathrm{C}\right)$ & $\mathrm{M}_{\mathrm{s}}\left({ }^{\circ} \mathrm{C}\right)$ & $\mathrm{A}_{\mathrm{s}}\left({ }^{\circ} \mathrm{C}\right)$ & $\mathrm{A}_{\mathrm{f}}\left({ }^{\circ} \mathrm{C}\right)$ \\
\hline $5 \mathrm{c}$ & bal. & 9,75 & 9,25 & 0,06 & -45 & -1 & -20 & 26 \\
\hline $10 \mathrm{a}$ & bal. & 10,4 & 3 & 0,1 & 81 & 121 & 100 & 165 \\
\hline 17 & bal. & 11,5 & 4 & 0,1 & 130 & 165 & 154 & 194 \\
\hline 18 & bal. & 11,8 & 4,1 & 0,1 & 70 & 110 & 95 & 145 \\
\hline
\end{tabular}

The training consisted in thermal cycling in a liquid bath (ethanol or silicon oil for low and high temperatures, respectively) under an external constant tensile load on cooling (applied with a weight) and stress free heating. The stress applied on cooling was $66 \mathrm{MPa}$. The induced TWSME was measured using a Perkin-EImer TMA-7 dilatometer. The microstructure was observed using optical and transmission electron microscopy (TEM). The thin foils for TEM were prepared by double-jet electropolishing in $1 / 3$ $\mathrm{HNO}_{3} 2 / 3 \mathrm{CH}_{3} \mathrm{OH}$ at $-40^{\circ} \mathrm{C}$ for samples transforming at elevated temperatures and in phosphoric acid saturated with $\mathrm{CrO}_{3}$ at room temperature (RT) for samples transforming at subzero temperatures.

\section{RESULTS AND DISCUSSION}

When the high Ms alloys (10a, 17 and 18) are quenched to RT in water, a strong martensite stabilization occurs, i.e. during heating in DSC, an endothermal peak is observed above $400^{\circ} \mathrm{C}$. On subsequent cooling, only the alloy 10a shows an exothermal peak related to the martensitic transformation. In alloys 17 and 18 , a tempering of martensite occurs during DSC heating. In order to get a reversible transformation, the alloys have to be quenched to temperatures above $A_{f}$ to reduce the martensite stabilization by quenching. Fig. 1 shows the relationship of $A_{s}$ and $A_{f}$ temperatures with the quenching bath temperature for alloy $10 a$. One can see that at low and high quenching bath temperatures an increment of reverse transformation temperatures is observed (due to martensite stabilization), while only after quenching to temperatures between 180 and $220^{\circ} \mathrm{C}$ are the values as characteristic for the alloy. Reheating of alloy 10a quenched to all applied bath temperatures until reverse transformation to $\beta$ phase causes destabilization of the alloy and a drop in reverse transformation temperatures (for subsequent cycles) to the values listed in Table 1 . In alloys 17 and 18 this phenomenon is not observed (only tempering of martensite), which indicates that increasing the $\mathrm{Al}$ content promotes the tendency to decomposition, as alfeady observed for alloys transforming at lower temperatures [12]. It is worth noting that the higher reverse transformation temperatures of the sample $10 \mathrm{a}$ quenched from $850^{\circ} \mathrm{C}$ to temperatures well above $\mathrm{A}_{\mathrm{f}}$ (i.e. $280^{\circ} \mathrm{C}$ in figure 1) are due to the martensite stabilization which occurs during the last quenching from $280^{\circ} \mathrm{C}$ in water at room temperature, and not at the first quench from $850^{\circ} \mathrm{C}$. In fact, if the samples are just air cooled from 
$280^{\circ} \mathrm{C}$ to room temperature, the transformation temperatures are obtained already in the first reverse transformation cycle.

Fig.2 shows the dilatometric curves obtained for alloy $10 \mathrm{a}$ quenched to $200^{\circ} \mathrm{C}$ after a different number of training cycles (applied tensile stress of $66 \mathrm{MPa}$ ). One can see that the amount of TWSME (defined by the spontaneous elongation during cooling) increases considerably with the training until 45 cycles. The measurements after 65 training cycles show already a small deterioration of the effect connected with a slight hysteresis widening. After a higher number of cycles this effect becomes clearer and the curves slightly shif to lower temperatures.

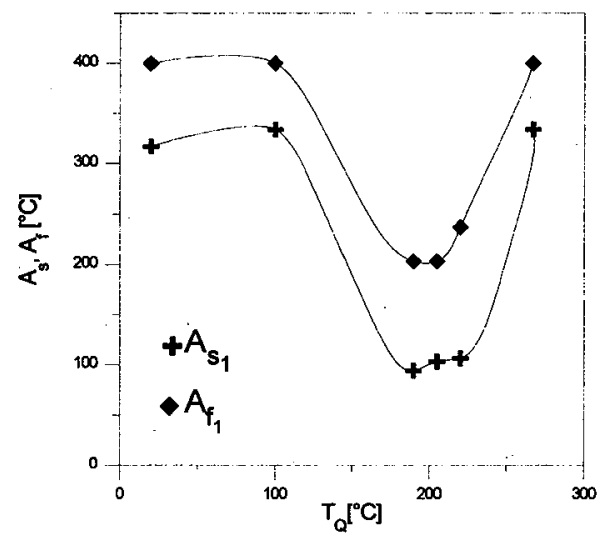

Figure 1. Martensitic transformation temperatures of alloy 10a as a function of the quenching bath temperature.

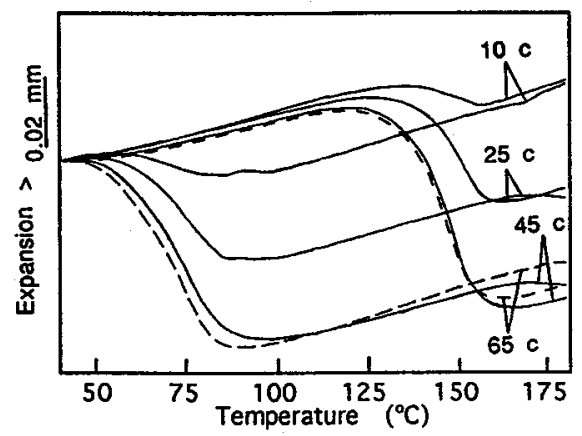

Figure 2. Dilatometric curves for alloy $10 \mathrm{a}$ quenched to $200^{\circ} \mathrm{C}$ after the indicated number of training cycles (training stress of $66 \mathrm{MPa}$ ).

Fig. 3 shows the evolution of the amount of TWSME with the number of training cycles for all the alloys. In the case of alloy $5 \mathrm{c}$, transforming at subzero temperatures, TWSME saturation occurs after about 50 cycles, with $1.4 \%$ elongation for a training stress of $66 \mathrm{MPa}$. Similar figures hold for alloy 18 transforming below $150^{\circ} \mathrm{C}$. On the other hand, for alloys 17 and $10 \mathrm{a}$, transforming close to $200^{\circ} \mathrm{C}$, the TWSME saturates after respectively 20 and 40 cycles, with much lower value (less than $0.4 \%$ ) of elongation/contraction. The lower the transformation temperatures, the higher the TWSME, although a higher number of training cycles is required. Comparing with other systems, TWSME saturation (at about $1 \%$ of elongation) was observed in CuAlZn alloys [1] which transform below $120^{\circ} \mathrm{C}$, after about 30 cycles. The high temperature transforming CuAlNi alloys needed $20-50$ training cycles for saturation [8] which also indicates the effect of temperature on the training efficiency. Calorimetric examination of 
trained alloys showed that the heats of transformation were considerably lower (about 30\%) than in the as-quenched samples, as reported for $\mathrm{CuZnAl}$ alloys [9]. The broadening of peaks after training and their shift towards lower temperatures appear for all alloys examined, as can be seen in Fig.4, where the calorimetric curves of as quenched and trained alloy 10a are presented. The shift towards lower temperatures can be explained by the formation of differently oriented variants (as suggested in [9]) and/or by the simultaneous formation of $\gamma_{1}^{\prime}$ and $\beta_{1}^{\prime}$ martensites, as indeed observed by TEM in the present alloys. When the two different martensites coexist, due to different crystal structures, some difficulties in the accommodation of the deformation arise, giving rise to higher irreversibilities [13].

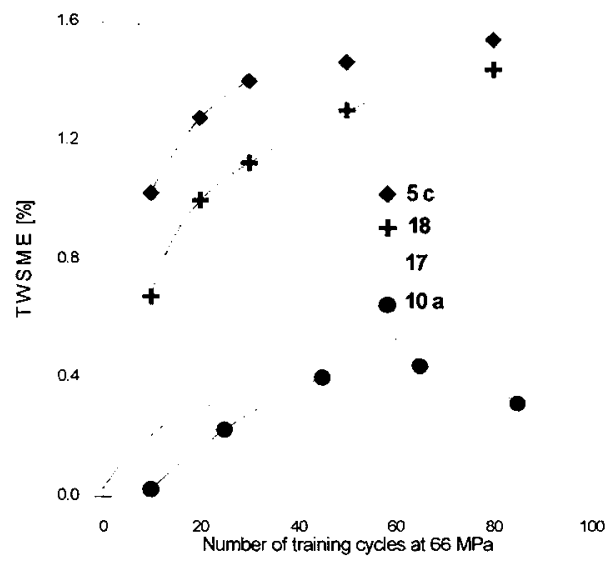

Figure 3. The two way shape memory effect (TWSME) as a function of training cycles at stress equal to $66 \mathrm{MPa}$ for all alloys.

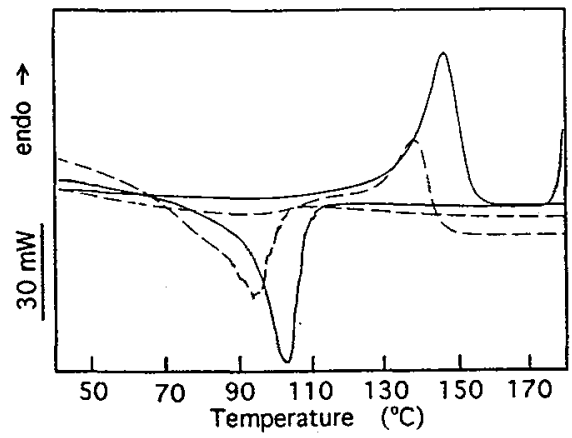

Figure 4. DSC curves recorded over the martensitic transformation range in alloy $10 \mathrm{a}$ as quenched to $200^{\circ} \mathrm{C}$ (full line) and after 85 training cycles under $66 \mathrm{MPa}$ (dashed line).

The lower values of transformation heat after training are connected with the presence of residual (and stabilised) martensite, as indeed observed in alloy $5 \mathrm{c}$ by optical microscopy (Fig. 5). Contrary to the observations of Stalmans et al [1], after overheating the trained samples the residual martensite does not disappear in the investigated alloys, as can be observed in Fig.5, where micrographs of the trained sample of alloy $5 \mathrm{c}$ before and after a 10 seconds of flash heating at $250^{\circ} \mathrm{C}$ are compared. The other alloys at room temperature were fully in martensitic state. They were heated in the calorimeter up to $400^{\circ} \mathrm{C}$, but no additional peaks above the reverse transformation were found. Moreover, on subsequent cooling, the alloy 17 did not show any peak due to martensitic transformation, most probably due to decomposition of $\beta_{1}$ 
and tempering of residual martensite. This indicates that in CuAlMn alloys the martensite stabilizes easily either thermally or upon deformation. The latter was already observed earlier in these alloys [14], where $10 \%$ of deformation by rolling prevented retransformation of martensite.

Earlier TEM observations of alloy $5 \mathrm{c}$ with 10 training cycles showed the presence of dislocation bands of high density [7]. Fig. 6 shows such a band in alloy 5c subjected to 80 training cycles. Most of dislocation bands are parallel to $\langle 110\rangle_{\beta}$ direction. The density of dislocations within the centre of a band is so high that single dislocations rarely can be distinguished, but no small martensite plates within bands, as observed in [15] after training, were found in the present case. The plates were often attached to bands but not within them.
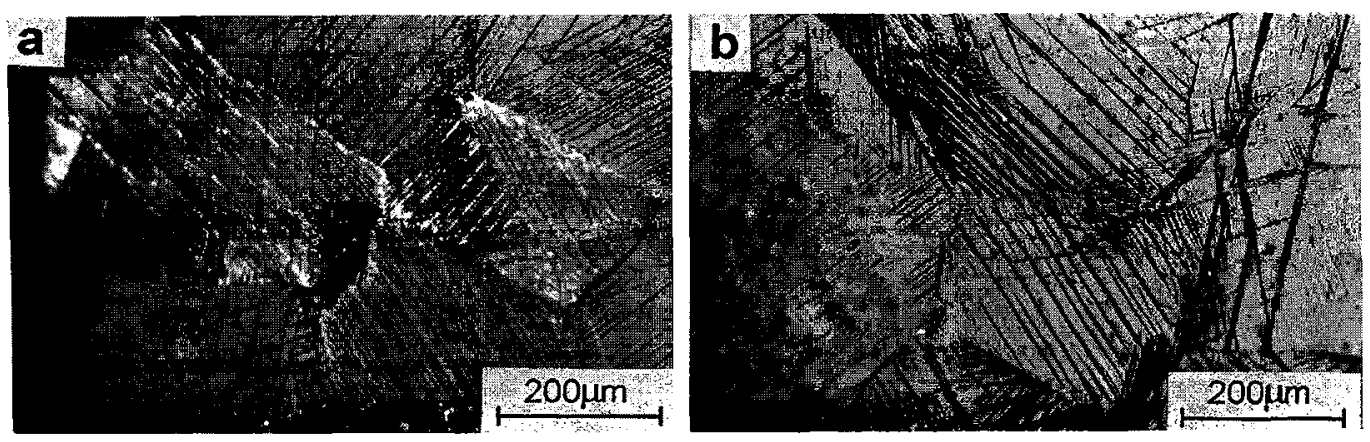

Figure 5. Optical micrographs of alloy $5 \mathrm{c}$ after 80 training cycles at $66 \mathrm{MPa}$ (a) and additionally flash heated for 10 seconds at $250^{\circ} \mathrm{C}(\mathrm{b})$.

A different dislocation structure was observed in alloys transforming at higher temperatures. For instance, Fig. 7 shows a TEM micrograph taken from alloy 10a subjected to 85 training cycles and heated in-situ in the microscope just above Af. This was done in order to observe the dislocation structure in $\beta$ phase since in martensite the contrast is disturbed by the frequent random stacking faults. The image shows a fairly uniform distribution of rather short dislocations even near TiB inclusion, where a concentration of dislocations was usually observed in the low temperature transforming alloy. The thermally activated dislocation motion is most probably one of the main reasons that no dislocation bands are formed in alloys transforming at higher temperatures. Consequently, dislocation bands cannot act as nucleation sites of preferred variants and training is less efficient. In fact, motion of dislocations has been observed by TEM during in situ heating experiments in $\mathrm{Cu}-\mathrm{Al}-\mathrm{Be}$ trained alloys [16].

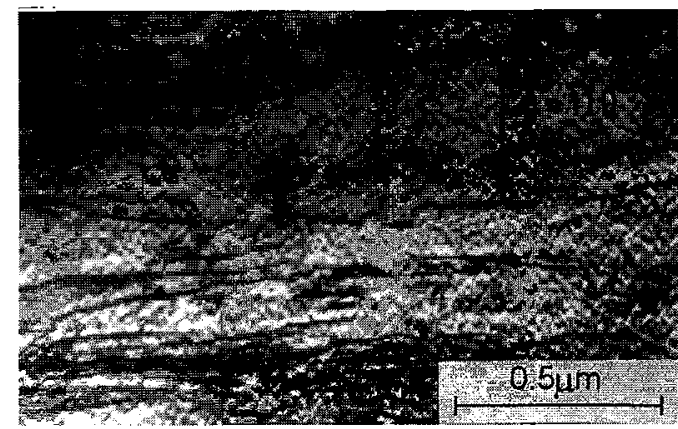

Figure 6. Transmission electron micrograph of sample 5 subjected to 80 training cycles under $66 \mathrm{MPa}$

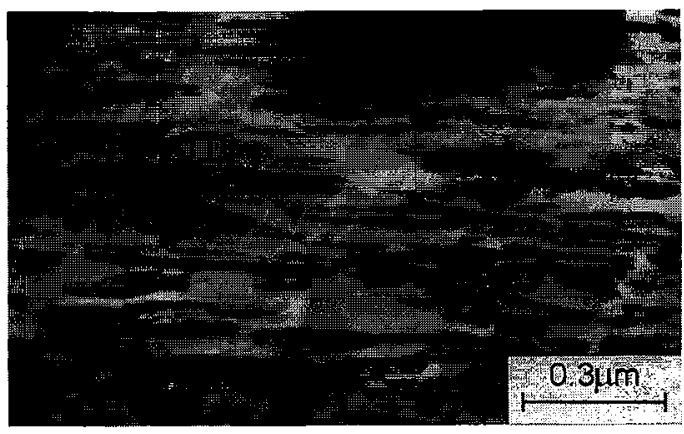

Figure 7. TEM micrograph of alloy 10a subjected to 85 trainig cycles under $66 \mathrm{MPa}$. The sample was heated in-situ above $A_{f}$ 


\section{CONCLUSIONS}

1. In CuAlMn alloys transforming at temperatures above $150^{\circ} \mathrm{C}$, the martensite is stabilized when the quenching bath temperature is about $50^{\circ} \mathrm{C}$ higher or lower than Af. The alloys, with lower Al content can be destabilized by overheating above $400^{\circ} \mathrm{C}$, but in other alloys tempering of martensite occurs and inhibits the further martensitic transformation.

2. Alloys transforming below $150^{\circ} \mathrm{C}$ attain up to $1.4 \% \mathrm{TWSME}$, saturating above 40 training cycles at 66 $\mathrm{MPa}$. Their structure shows after training a substantial amount of residual martensite and frequent deformation bands along $<110>\beta$ directions.

3. Alloys transforming above $160^{\circ} \mathrm{C}$ attain much smaller TWSME, saturated after a lower number of training cycles. This is most probably related to the thermal motion of dislocations preventing formation of dislocation bands.

4. The transformation heat is considerably smaller after training due to residual martensite, and the transformation temperatures are shifted to lower temperatures, which is most probably caused by formation of different structures and variants of martensite after training.

\section{Acknowledgements}

Partial financial support from the DGICyT, Spain (research projects num. PB94-1173 and PB95-0340) is gratefully acknowledged.

\section{References}

[1] Stalmans R., Van Humbeeck J. and Delaey L.; Acta metall. mater. 40 (1992) 501, 2921

[2] Quingfu O., Hurtado I., Stalmans R. and Van Humbeeck J.; J. de Physique IV, Colloque C2, 5, (1995) C2-181

[3] Contardo L. and Guénin G.; Acta metall. mater. 30 (1994) 1267

[4] Sakamoto H., Sugimoto K., Nakamura Y., Tanaka A. and Shimizu K.; Mat. Trans. JIM 32 (1991) 128

[5] Guilemany J.M. and Fernández J.; Scripta metall. mater. 30 (1994) 59

[6] Cingolani E., Ahlers M. and Sade M.; Acta metall. mater. 43 (1995) 2451

[7] Dutkiewicz J., Cesari E. and Pons J.; J. de Physique IV Colloque C8, 5 (1995) C8-995

[8] Rodriguez P.; Ph D. Thesis INSA Lyon, 1989

[9] Xu H. and Tan S.; Scripta metall. mater. 33 (1995) 749

[10] Mellor B.G., Guilemany J.M. and Fernández J.; J. de Physique IV, Colloque C4, 1 (1991) C4-457

[11] Mellor G.B., Hernaez J., and Lopez del Castillo C., Scripta Met.,20, (1986) 839

[12] Dutkiewicz J. and Cesari E.; J. de Physique Colloque C8, 5 (1995) C8-199

[13] Van Humbeeck J., Van Hulle D., Delaey L., Ortín J., Segui C. and Torra V.; Trans. of The Japan Inst. of Metals 28 (383)

[14] Dutkiewicz J.; J. Materials Sci., 29 (1994) 6249

[15] Lovey F.C., Rodríguez P.L., Malarría J., Sade M. and Torra V.; J. de Physique IV, Colloque C2, 5 (1995) C2-287

[16] Flores-Zúñiga H., Ríos-Jara D. and Guénin G.; Scripta metall. mater. 31 (1994) 1233 